\title{
Possibility of quinine transformation in food products: LC-MS and NMR techniques in analysis of quinine derivatives
}

\author{
Andrzej L. Dawidowicz ${ }^{1} \cdot$ Katarzyna Bernacik $^{1} \cdot \operatorname{Rafał~Typek}^{1} \cdot$ Marek Stankevič $^{2}$
}

Received: 25 January 2017 / Revised: 9 June 2017 / Accepted: 24 June 2017 / Published online: 5 July 2017

(C) The Author(s) 2017. This article is an open access publication

\begin{abstract}
Quinine is an alkaloid consisting of two major systems: quinoline and quinuclidine. It receives the attention of scientists because of its several medical properties: antimalarial, painkilling and fever-reducing properties. Moreover, it is widely used in food industry as a flavor component. Although the method of quinine synthesis is known, the most cost-effective is its isolation from its natural source, the bark of Cinchona tree. Liquid-solid extraction is the predominantly applied method for the isolation of active biological compounds from different plants. We found that the heating of the quinine in phosphoric buffer solution with low $\mathrm{pH}$ produced at least five compounds, whereas the heating of the quinine in alcohol/phosphoric buffer solution with decreased $\mathrm{pH}$ produced at least eight compounds. The formation of hydroxy and alkoxy adducts has not yet been reported. We observed that the amount of each formed component is dependent on the heating time, alcohol concentration in alcoholic/buffer mixture and $\mathrm{pH}$. The presented results are particularly important in the context of the use of quinine as food ingredient, because quinine derivatives, quinine structural isomers and their derivatives can be formed in significant amounts and their influence on the human body has not been fully explored yet.
\end{abstract}

Electronic supplementary material The online version of this article (doi:10.1007/s00217-017-2940-0) contains supplementary material, which is available to authorized users.

Andrzej L. Dawidowicz

dawid@ poczta.umcs.lublin.pl

1 Faculty of Chemistry, Maria Curie Sklodowska University, Pl. Maria Curie Sklodowska 3, 20-031 Lublin, Poland

2 Faculty of Chemistry, Maria Curie Sklodowska University, Gliniana 33, 20-614 Lublin, Poland
Keywords Quinine extraction · Flavor component . Food additive · Quinine stability · LC-MS analysis · NMR analysis

\section{Introduction}

Quinine is a white crystalline alkaloid occurring naturally in the bark of the cinchona tree, which grows in South America. Its molecule consists of two major fused-ring systems: the aromatic quinoline and the bicyclic quinuclidine. Quinine has many medicinal applications due to its feverreducing, painkilling and anti-inflammatory properties. It was the first medication for malaria and is still used today to treat some forms of the disease caused by the parasite Plasmodium falciparum. Another generally known quinine property is its bitter taste. Nowadays, it is widely used as a flavor ingredient for bitterish drinks, and food products, yet in limited concentration. Although quinine can be synthesized, cinchona trees remain a much cheaper source of this alkaloid on the industrial scale [1-5].

The knowledge of the medical and taste properties of quinine is the reason of on-going detailed investigations of its properties and searching for effective isolation methods from plant material for preparative and analytical purposes. High temperature liquid-solid extraction is the most popular method of plant component isolation [6], including quinine, the process in which organic solvents of different polarity are most frequently employed for plant extraction. Some quinine isolation procedures involve alcohol/water mixtures or acidified water as extracting mediums [7, 8].

According to earlier reports [9-12], the high temperature extraction of chlorogenic acid or rutin with water or alcohol/water solutions causes their isomerization and transformation. More than 20 derivatives and reaction 
products of each of the mentioned compounds with water and/or alcohol can be formed in such process. The purpose of the present study was to determine the thermal stability of quinine during its extraction by water and alcohol/water mixtures. To answer this question, we investigated quinine transformation process during the heating of its methanol, water, buffered methanol ( $\mathrm{pH} 2-9)$ and buffered water $(\mathrm{pH}$ 2-9) solutions under reflux.

\section{Materials and methods}

\section{Materials and reagents}

Sodium phosphate, phosphoric acid, methanol, acetic acid, dichloromethane, sodium bicarbonate, anhydrous magnesium sulfate (all of analytical grade) and acetonitrile (HPLC) were purchased from the Polish Chemical Plant POCh (Gliwice, Poland). Quinine standard, formic acid and deuterated chloroform were from Sigma-Aldrich (Seelze, Germany). Water was purified on the Milli-Q system from Millipore (Millipore, Bedford, MA, USA). Bitter Lemon and Indian Tonic (both from Schweppes) were used as samples of food products.

\section{Simulated quinine extraction}

The investigations of the quinine transformation process were performed by heating under reflux its solutions in water or methanol or buffer ( $\mathrm{pH} 2-9)$ or methanol/buffer (pH 2-9) mixture containing 25 or 50 or $75 \mathrm{v} / \mathrm{v}$ of alcohol. Phosphate buffers were used in the experiments. The glass equipment for the experiments consisted of a boiling flask $(100 \mathrm{ml})$ and a small condenser. The heated quinine solutions contained $10 \mathrm{mg}$ of the compound in $50 \mathrm{ml}$ of a given solvent. Individual quinine solutions were heated for 0.5 and 1 and 1.5 and $2 \mathrm{~h}$. After heating, the obtained solutions were subjected to LC-MS-PDA analysis.

\section{Heating of beverages containing quinine}

To find if quinine transformation process occurs in real samples Bitter Lemon and Indian Tonic beverages were heated under reflux for $0.5 \mathrm{~h}$. After heating, the obtained samples were subjected to LC-MS-PDA analysis.

\section{HPLC measurements}

The chromatographic measurements were performed using LC/MS from Finnigan (LCQ Advantage Max) equipped with autosampler and column thermostat (Surveyor Autosampler Plus) pump (Surveyor LC Pump Plus), the ion-trap mass spectrometric system (ThermoElectron
Corporation, San Jose, CA) and a diode array detector from Finningan (Surveyor PDA Plus Detector). A Gemini C18 column $(4.6 \times 100 \mathrm{~mm}, 3 \mu \mathrm{m})$ (Phenomenex, USA) was employed for chromatographic separation, which was performed using gradient elution. The mobile phase A was $25 \mathrm{mM}$ formic acid in water; the mobile phase B was $25 \mathrm{mM}$ formic acid in acetonitrile. The gradient program started at 5\% B increasing to $35 \%$ for $60 \mathrm{~min}$, next $35 \% \mathrm{~B}$ to $95 \% \mathrm{~B}$ for $12 \mathrm{~min}$, and ended with isocratic elution followed $(95 \% \mathrm{~B})$ for $3 \mathrm{~min}$. The total run time was $75 \mathrm{~min}$ at the mobile phase flow rate $0.4 \mathrm{~mL} / \mathrm{min}$. The column temperature was $25^{\circ} \mathrm{C}$. In the course of each run, PDA spectra in the range 190-600 $\mathrm{nm}$ and MS spectra in the range of $100-2000 \mathrm{~m} / \mathrm{z}$ were collected continuously. Each sample was analyzed two times using the TIC function and the SIM function. The SIM function was used to better visualize the chromatographic separation and to remove the signal connected with buffer components. The time periods and monitored ions were as follows:

0-5 $(343 \mathrm{~m} / \mathrm{z}), 5-8 \mathrm{~min}(325 \mathrm{~m} / \mathrm{z}), 8-13(357 \mathrm{~m} / \mathrm{z})$, 13-17 $\mathrm{min}(343 \mathrm{~m} / \mathrm{z}), 17-23 \mathrm{~min}(325 \mathrm{~m} / \mathrm{z}), 23-24$ $(357 \mathrm{~m} / \mathrm{z}), 24-28(343 \mathrm{~m} / \mathrm{z}), 28-30(325 \mathrm{~m} / \mathrm{z}), \quad 30-90$ $(357 \mathrm{~m} / \mathrm{z})$.

The column effluent was ionized by electrospray (ESI). The ESI needle potential was $4.5 \mathrm{kV}$ in the positive ionization mode. To identify quinine isomers, the function of secondary $\left(\mathrm{MS}^{2}\right)$ and ternary $\left(\mathrm{MS}^{3}\right)$ ion fragmentation was applied. The collision energy for each examined compound was the same (25\%). For confirmation, the HRMS analysis was additionally carried out on the HPLC system coupled to a linear trap quadrupole-Orbitrap mass spectrometer (LTQ-Orbitrap Velos from Thermo Fisher Scientific, San Jose, CA) equipped with an ESI source. ESI was operated in positive polarity modes under the following conditions: spray voltage $-3.5 \mathrm{kV}$; sheath gas -40 arb. units; auxiliary gas - 10 arb. units; sweep gas - 10 arb. units; and capillary temperature- $320{ }^{\circ} \mathrm{C}$. Nitrogen $(>99.98 \%)$ was employed as sheath, auxiliary and sweep gas. The scan cycle used a full-scan event at the resolution of 60,000. The amounts of quinine and its isomers were estimated by relating their chromatographic responses (the SIM signal height) to the calibration curve for quinine.

\section{Sample preparation for NMR and $\mathrm{MS}^{2}$ analysis}

To get greater amount of quinine derivatives for NMR analysis, the quinine transformation reaction was performed in more reactive environment. In a round-bottom flask $(100 \mathrm{~mL})$, equipped with magnetic stirrer and reflux condenser, quinine $(200 \mathrm{mg})$ was mixed with $\mathrm{AcOH} / \mathrm{H}_{2} \mathrm{O}(2: 1$, $50 \mathrm{~mL}$ ). The mixture was heated at $80{ }^{\circ} \mathrm{C}$ for $48 \mathrm{~h}$, and then cooled to rt. To this mixture, saturated $\mathrm{NaHCO}_{3}$ was added until $\mathrm{pH}$ reached approximately $7.5-8$. The obtained 
mixture was extracted with dichloromethane $(3 \times 30 \mathrm{~mL})$ and then the combined organic phases were dried over $\mathrm{MgSO}_{4}$, filtered and evaporated to dryness. The residue was purified using flash chromatography (homemade system) with $\mathrm{CHCl}_{3}: \mathrm{MeOH} 15: 1$ as eluent. Two fractions were subjected to NMR and $\mathrm{MS}^{2}$ analysis. These fractions, before NMR and $\mathrm{MS}^{2}$ measurements, were dried using a vacuum evaporator and the obtained dry matters were dissolved in $\mathrm{CDCl}_{3}$ for $\mathrm{NMR}$ analysis and in $\mathrm{MeOH}$ for $\mathrm{MS}^{2}$ analysis.

\section{NMR analysis}

The NMR measurements were performed using NMR system from Bruker (Ascend 500). The resulting $\mathrm{CDCl}_{3}$ solutions of the synthesized substances were examined using ${ }^{1} \mathrm{H},{ }^{13} \mathrm{C}$ and DEPT function (and additionally, see supplementary materials, 2D NMR techniques, including ${ }^{1} \mathrm{H}-{ }^{1} \mathrm{H}$ COSY, HSQC and HMBC experiments).

The following results were obtained:

\section{Fraction 1}

${ }^{1} \mathrm{H}$ NMR (500 MHz, $\left.\mathrm{CDCl}_{3}\right) \quad \delta$ 0.97-1.04 (m, 1H), 1.47-1.54 (m, 1H), 1.63-1.69 (m, 2H), 1.74-1.79 (m, 1H), 2.34-2.41 (m, 1H), 2.81-2.90 (m, 2H), 3.15-3.23 (m, 1H), 3.26-3.36 (m, 2H), $3.96(\mathrm{~s}, 3 \mathrm{H}), 4.97-5.05(\mathrm{~m}, 2 \mathrm{H}), 5.07$ $\left(\mathrm{d}, J_{\mathrm{H}-\mathrm{H}}=10.1 \mathrm{~Hz}, 1 \mathrm{H}\right), 5.72-5.79(\mathrm{~m}, 1 \mathrm{H}), 7.39(\mathrm{dd}$, $\left.J_{\mathrm{H}-\mathrm{H}}=2.8 \mathrm{~Hz}, J_{\mathrm{H}-\mathrm{H}}=9.1 \mathrm{~Hz}, 1 \mathrm{H}\right), 7.42\left(\mathrm{~d}, J_{\mathrm{H}-\mathrm{H}}=4.7 \mathrm{~Hz}\right.$, $1 \mathrm{H}), 7.66\left(\mathrm{~d}, J_{\mathrm{H}-\mathrm{H}}=2.8 \mathrm{~Hz}, 1 \mathrm{H}\right), 8.04\left(\mathrm{~d}, J_{\mathrm{H}-\mathrm{H}}=9.1 \mathrm{~Hz}\right.$, $1 \mathrm{H}), 8.75\left(\mathrm{~d}, J_{\mathrm{H}-\mathrm{H}}=4.4 \mathrm{~Hz}, 1 \mathrm{H}\right)$.

${ }^{13} \mathrm{C} \mathrm{NMR}\left(126 \mathrm{MHz}, \mathrm{CDCl}_{3}\right) \delta 25.0,27.2,27.7,39.6$, $40.8,55.6,55.7,61.6,71.2,102.5,115.0,120.1,121.4$, $128.1,131.7,141.0,144.1,144.9,147.6$.

\section{Fraction 2}

${ }^{1} \mathrm{H}$ NMR (500 MHz, $\left.\mathrm{CDCl}_{3}\right) \quad \delta$ 1.21-1.29 (m, 1H), $1.32-1.41(\mathrm{~m}, 1 \mathrm{H}), 1.50-1.59(\mathrm{~m}, 1 \mathrm{H}), 1.68-1.73(\mathrm{~m}$, $1 \mathrm{H}), 1.79-1.84(\mathrm{~m}, 1 \mathrm{H}), 1.92-2.01(\mathrm{~m}, 1 \mathrm{H}), 2.04-2.12$ (m, 1H), 2.43-2.49 (m, 1H), 2.58-2.65 (m, 1H), 2.98-3.17 $(\mathrm{m}, 3 \mathrm{H}), 3.94(\mathrm{~s}, 3 \mathrm{H}), 5.05-5.14(\mathrm{~m}, 2 \mathrm{H}), 5.51-5.60(\mathrm{~m}$, $1 \mathrm{H}), 7.41\left(\mathrm{dd}, \mathrm{J}_{\mathrm{H}-\mathrm{H}}=2.8 \mathrm{~Hz}, \mathrm{~J}_{\mathrm{H}-\mathrm{H}}=9.1 \mathrm{~Hz}, 1 \mathrm{H}\right), 7.57(\mathrm{~d}$, $\left.\mathrm{J}_{\mathrm{H}-\mathrm{H}}=4.4 \mathrm{~Hz}, 1 \mathrm{H}\right), 7.81\left(\mathrm{~d}, \mathrm{~J}_{\mathrm{H}-\mathrm{H}}=2.8 \mathrm{~Hz}, 1 \mathrm{H}\right), 8.04(\mathrm{~d}$, $\left.\mathrm{J}_{\mathrm{H}-\mathrm{H}}=9.1 \mathrm{~Hz}, 1 \mathrm{H}\right), 8.85\left(\mathrm{~d}, \mathrm{~J}_{\mathrm{H}-\mathrm{H}}=4.7 \mathrm{~Hz}, 1 \mathrm{H}\right)$.

${ }^{13} \mathrm{C}$ NMR $\left(126 \mathrm{MHz}, \mathrm{CDCl}_{3}\right) \delta 28.3,31.3,38.9,39.6$, $46.4,48.1,52.1,55.6,102.3,116.8,120.0,122.8,125.2$, $131.3,139.5,140.6,145.7,147.0,159.3,204.1$.

\section{Statistical analysis}

All the results are presented as the mean of three independent measurements $(n=3)$. Differences in the concentration of the formed quinine isomers were compared using variance analysis (ANOVA, $p=0.05$ ). Differences in the studied groups were considered significant for $p$ values lower than 0.05 and $F$ values higher than 2.87. Variance analysis revealed statistically significant differences for the tested groups.

\section{Results and discussion}

Figure 1 presents the exemplary chromatograms of quinine solutions in water (Fig. 1a), methanol (Fig. 1b), phosphoric buffer (pH 9) (Fig. 1c), methanol/phosphoric buffer (pH 9) (75/25 v/v) (Fig. 1d), phosphoric buffer (pH 6) (Fig. 1e), methanol/phosphoric buffer ( $\mathrm{pH} \mathrm{6)}(75 / 25 \mathrm{v} / \mathrm{v})$ (Fig. 1f), phosphoric buffer ( $\mathrm{pH}$ 2) (Fig. 1g) and methanol/phosphoric buffer ( $\mathrm{pH}$ 2) (75/25 v/v) (Fig. 1h), all heated under reflux for $0.5 \mathrm{~h}$. The samples imitate the quinine extracts obtained during its water or methanol/water extraction under reflux.

The chromatograms of aqueous, methanolic and alkaline extracts (Fig. 1a-d) contain only one peak which corresponds with quinine.

Slight acidic ( $\mathrm{pH} \mathrm{6)}$ water and methanol/water extracts (see Fig. 1e, f) contain, in addition to the parent substance, two compounds formed as a result of quinine transformation and/or degradation. The molecular weights of two of them (peaks 2 and 3) are the same as the molecular weight of quinine $(\mathrm{m} / \mathrm{z}=325)$. Moreover, they have the same fragmentation pathway (see $\mathrm{MS}^{2}$ and $\mathrm{MS}^{3}$ data in Table 1) and very similar PDA spectra (see Fig. 1 in supplementary materials). Hence, these two quinine derivatives can be its conformers or isomers. NMR data (see Fig. 2 in supplementary materials) prove that they are quinine structural isomers,

(S)-(6-methoxyquinolin-4-yl)((2S,4S,8R)-8-vinylquinuclidin-2-yl)methanol-epi-Quinine (epi-Qu) (peak 2) and

3-[(3R,4R)-3-vinylpiperidin-4-yl]-1-(6-methoxyquinolin-4-yl)-1-propanone-Quinotoxine (Qu-tox) (peak 3),

and not quinine conformers.

The structures of both epi-quinine and quinotoxine were unambigously solved using 2D NMR techniques, including ${ }^{1} \mathrm{H}-{ }^{1} \mathrm{H}$ COSY, HSQC and HMBC experiments (see Fig. 3 in supplementary materials). Every 2D NMR experiment shows the correct bonding and correct neighboring effect for every atom. There are some discrepancies between our experimental and literature data [13, 14] (see Tables 1 and 2 in supplementary materials); however, they might arise from solvent and/or additive influence. It was observed in our laboratory that the addition 

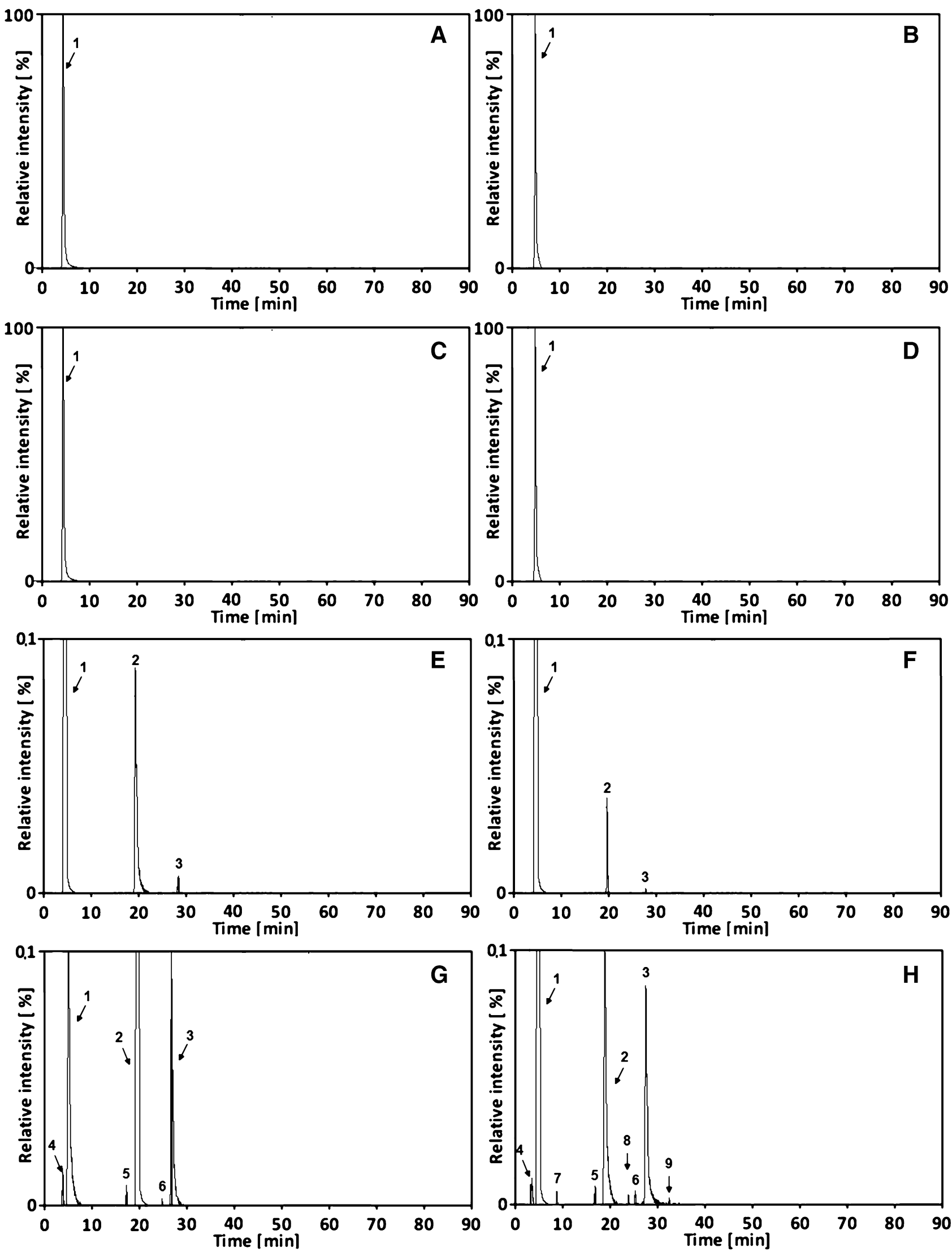
4Fig. 1 Exemplary chromatograms of quinine solutions in water (a), methanol (b) phosphoric buffer (pH 9) (c), methanol/phosphoric buffer (pH 9) (75/25 v/v) (d), phosphoric buffer (pH 6) (e), methanol/phosphoric buffer (pH 6) (75/25 v/v) (f), phosphoric buffer ( $\mathrm{pH} 2)$ (g) and methanol/phosphoric buffer ( $\mathrm{pH} 2)(75 / 25 \mathrm{v} / \mathrm{v})(\mathbf{h})$, all heated under reflux for $0.5 \mathrm{~h}$. Peak numbers correspond to compounds numbers given in Table 1

of sub-molar amounts of acid shifts selected signals significantly in both ${ }^{1} \mathrm{H}$ and ${ }^{13} \mathrm{C}$ NMR spectra. $\mathrm{MS}^{2}$ data for Fraction I (epi-Qu) and Fraction II (Qu-tox) additionally confirm validity of the performed identification (see Table 3 in supplementary materials).

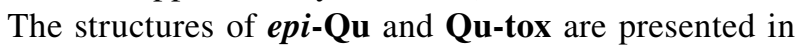
Fig. 2. Such identification is in agreement with the work of $[15,16]$ who reported the transformation of quinine to the mentioned isomers in the strongly acidic environment. The results presented in Fig. $1 \mathrm{e}$ and $\mathrm{f}$ show that the transformation of quinine to its structural isomers can take place also in a less acidic environment. The absence of quinine isomers in the alkaline solution and their concentration increase in more and more acidic extracting solutions discussed in detail later confirm the influence of $\mathrm{pH}$ on their formation. Yet, as the formation of conformers is not $\mathrm{pH}$ dependent [17], they cannot be considered as such.

The similarity of the quinine, epi-Qu and Qu-tox PDA spectra confirms additionally the lack of structural difference in the quinoline part and the chromophore part of the considered molecules. The longer retention of Qu-tox (peak 3) in relation to $\mathbf{Q u}$ and $\boldsymbol{e p i - Q u}$ in RP-HPLC system results from its higher hydrophobicity caused by the change of more polar hydroxyl group to carbonyl one.

Figure 1e and f, in which peak 2 corresponds with $\boldsymbol{e p i}$ Qu and Qu-tox is represented by peak 3, indicates that different amounts of individual structural quinine isomers are formed during the high temperature extraction process in the acidic environment. This fact suggests different formation kinetics of both $\mathbf{Q u}$ isomers.

The strongly acidic ( $\mathrm{pH}$ 2) water extract (Fig. 1g) contains, besides the parent substance, five additional compounds formed as a result of quinine transformation and/ or degradation. Two of them (peaks 2 and 3) are epi-Qu and Qu-tox, the structural quinine isomers described above. Three other compounds (peaks 4, 5 and 6 in Fig. $1 \mathrm{~g}$ ) have been identified as water adducts of quinine and its structural isomers formed by chemical addition of water to double bond $(-\mathrm{C}=\mathrm{C}-$ ) of aliphatic moiety or by coordination of water to one of nitrogen in $\mathbf{Q u}$ and its isomers:

$(R)$-(6-methoxyquinolin-4-yl) ((2S, 4S, 8R)-8-(1hydroxyethyl)-quinuclidin-2-yl)methanol or quinine and water associate (peak 4), (Qu-OH),
(S)-(6-methoxyquinolin-4-yl) ((2S,4S,8R)-8-(1hydroxyethyl)-quinuclidin-2-yl)methanol or epi-quinine and water associate (peak 5) (epi-Qu-OH) and

3-[(3R,4R)-3-(1-hydroxyethyl)-piperidin-4-yl]-1-(6methoxyquinolin-4-yl)-1-propanone or quinotoxine and water associate (peak 6) (Qu-tox-OH).

The identification can be justified by the following arguments. The molecular weights of the compounds represented by peaks 4,5 and 6 are almost the same (Table 2) and exceed the molecular weight of quinine and its isomers by $18.0108,18.0101$ and $18.0103 \mathrm{Da}$, respectively, which correspond to the molecular weight of water, 18.0106 Da.

The introduction of the $\mathrm{OH}$ group to any molecule increases its polarity, which shortens its retention in the RP chromatographic system. The retention times of the considered compounds are shorter than the retention time of quinine and its structural isomers, indicating their higher polarity than the polarity of their precursor. Moreover, the quantitative relations among hydroxyl derivatives resemble those among their precursors. All these arguments support the correctness of the identification. It has also been found that the $\mathrm{MS}^{\mathrm{n}}$ spectra of peaks 4, 5 and 6 are less helpful in differentiating hydroxylated quinine derivatives as all the derivatives are fragmented to ions of very similar mass and intensity (Table 1). NMR identification of these compounds was impossible due to their small amounts in reaction mixtures.

Figure 1f shows the exemplary chromatogram of methanol/phosphoric buffer ( $\mathrm{pH} 2)(75 / 25 \mathrm{v} / \mathrm{v})$ solution of quinine heated under reflux for $0.5 \mathrm{~h}$. The chromatogram illustrates that besides the parent substance, eight compounds appear in the solution. Five of them were identified when quinine was heated in acidic water solution:

epi-Qu, Qu-tox, Qu-OH, epi-Qu -OH and Qu-tox-OH.

Three other ones are methanolic adducts of quinine and its structural isomers:

$(R)$-(6-methoxyquinolin-4-yl) $((2 \mathrm{~S}, 4 \mathrm{~S}, 8 \mathrm{R})-8-(1-$ methoxyethyl)-quinuclidin-2-yl)methanol or quinine and methanol associate (peak 7) (Qu-OMe),

$(S)$-(6-methoxyquinolin-4-yl) ((2S,4S,8R)-8-(1methoxyethyl)-quinuclidin-2-yl)methanol or epi-quinine and methanol associate (peak 8) (epi-Qu-OMe) and

3-[(3R,4R)-3-(1-methoxyethyl)-piperidin-4-yl]-1-(6methoxyquinolin-4-yl)-1-propanone or quinotoxine and methanol associate (peak 9) (Qu-tox-OMe).

The alcoholic adducts were identified from the molecular weights of the compounds (peaks 7,8 and 9), which were greater than the molecular weight of quinine and its isomers by the molecular weight of methanol. If methanol molecule is attached to double bond, then methoxyl groups is located at carbon atom of higher order. This supposition is in agreement with [17]. 
Table 1 The $\mathrm{MS}^{\mathrm{n}}$ data for quinine and quinine transformation products

\begin{tabular}{|c|c|c|c|c|c|c|c|c|c|}
\hline \multirow[t]{3}{*}{ Peak no. } & \multicolumn{2}{|l|}{$\mathrm{MS}^{1}$} & \multirow{2}{*}{\multicolumn{2}{|c|}{$\begin{array}{l}\mathrm{MS}^{2} \\
\text { Secondary peak }\end{array}$}} & \multicolumn{4}{|l|}{$\mathrm{MS}^{3}$} & \multirow[t]{3}{*}{ Compounds } \\
\hline & \multirow{2}{*}{$\begin{array}{l}\text { Parent ion } \\
\mathrm{m} / \mathrm{z}\end{array}$} & \multirow{2}{*}{$\begin{array}{l}\text { Base peak } \\
m / z\end{array}$} & & & \multirow{2}{*}{$\begin{array}{l}\text { Parent ion } \\
m / z\end{array}$} & \multirow{2}{*}{$\begin{array}{l}\text { Base peak } \\
m / z\end{array}$} & \multicolumn{2}{|c|}{ Secondary peak } & \\
\hline & & & $m / z$ & Intensity (\%) & & & $m / z$ & Intensity (\%) & \\
\hline \multirow[t]{3}{*}{1} & \multirow[t]{3}{*}{325.1} & \multirow[t]{3}{*}{307.2} & 184.5 & 37.8 & \multirow[t]{3}{*}{-} & \multirow[t]{3}{*}{-} & \multirow[t]{3}{*}{-} & \multirow[t]{3}{*}{-} & \multirow[t]{3}{*}{ Qu } \\
\hline & & & 264.4 & 15.1 & & & & & \\
\hline & & & 253.4 & 6.8 & & & & & \\
\hline \multirow[t]{3}{*}{2} & \multirow[t]{3}{*}{325.1} & \multirow[t]{3}{*}{307.2} & 184.4 & 38.1 & \multirow[t]{3}{*}{-} & \multirow[t]{3}{*}{-} & \multirow[t]{3}{*}{-} & \multirow[t]{3}{*}{-} & \multirow[t]{3}{*}{ epi-Qu } \\
\hline & & & 264.4 & 14.7 & & & & & \\
\hline & & & 253.3 & 6.9 & & & & & \\
\hline \multirow[t]{3}{*}{3} & \multirow[t]{3}{*}{325.1} & \multirow[t]{3}{*}{307.3} & 184.4 & 39.1 & - & - & - & - & Qu-tox \\
\hline & & & 264.5 & 13.9 & & & & & \\
\hline & & & 253.4 & 6.7 & & & & & \\
\hline 4 & 343.2 & 325.3 & 307.2 & 5.2 & 325.2 & 307.2 & 184.3 & 34.2 & Qu-OH \\
\hline & & & & & & & 264.3 & 13.5 & \\
\hline & & & & & & & 253.4 & 7.9 & \\
\hline 5 & 343.1 & 325.2 & 307.2 & 6.1 & 325.1 & 307.1 & 184.4 & 39.9 & epi-Qu-OH \\
\hline & & & & & & & 264.4 & 12.7 & \\
\hline & & & & & & & 253.4 & 4.4 & \\
\hline 6 & 343.2 & 325.2 & 307.1 & 7.7 & 325.1 & 307.2 & 184.5 & 41.2 & Qu-tox-OH \\
\hline & & & & & & & 264.5 & 11.4 & \\
\hline & & & & & & & 253.4 & 2.6 & \\
\hline 7 & 357.1 & 325.3 & 307.1 & 7.4 & 325.2 & 307.2 & 184.5 & 37.7 & Qu-OMe \\
\hline & & & & & & & 264.4 & 17.7 & \\
\hline & & & & & & & 253.4 & 6.4 & \\
\hline 8 & 357.1 & 325.2 & 307.2 & 4.5 & 325.1 & 307.2 & 184.4 & 33.4 & epi-Qu-OMe \\
\hline & & & & & & & 264.3 & 14.1 & \\
\hline & & & & & & & 253.4 & 5.7 & \\
\hline 9 & 357.2 & 325.2 & 307.2 & 5.6 & 325.1 & 307.2 & 184.4 & 37.1 & Qu-tox-OMe \\
\hline & & & & & & & 264.5 & 11.1 & \\
\hline & & & & & & & 253.4 & 5.7 & \\
\hline
\end{tabular}

The retention time of all methanolic adducts is longer than that of quinine and its structural isomers. In the RP system, the introduction of alkyl group to the molecule increases its hydrophobicity, thus leading to stronger hydrophobic interaction with the stationary phase and to the elongation of retention times. Methoxy derivatives of quinine and its isomers elute in the same order as their precursors. Moreover, the quantitative relation among methoxy derivatives resembles those among their precursors. During $\mathrm{MS}^{\mathrm{n}}$ analysis of all the alcohol adducts of quinine and its isomers, the $357 \mathrm{~m} / \mathrm{z}$ ion appears, fragmented in the same way as the quinine molecular ion $(325 \mathrm{~m} / \mathrm{z})$. UV-Vis spectra of all methoxy quinine and all its structural isomers are very similar.

To confirm or exclude the presence of quinine derivatives in commercially available beverages, Tonic and Bitter Lemon (both from Schweppes) were selected for the experiments. Figure 3 presents exemplary chromatograms of the mentioned beverages before and after their heating under reflux for $0.5 \mathrm{~h}$. As results from its analysis, the initial beverages contain quinine, epi-quinine, quinotoxine and small amounts of their hydroxyl derivatives. After heating of the examined beverages, the quinine quantity decrease with simultaneous increase of epi-quinine, quinotoxine and hydroxy-derivatives of quinine, epi-quinine and quinotoxine is observed.

Figure 4 presents the influence of heating time on the amount of quinine remaining in the heated quinine solution (Fig. 4a) and on the amount of individual quinine derivatives (epi-Qu, Qu-tox, Qu-OH, epi-Qu-OH and Qu-tox$\mathbf{O H}$ - Fig. 4b-f, respectively); all of them formed during the heating of quinine in phosphoric buffer at given $\mathrm{pH}(\mathrm{pH}$ 2-diamonds; $\mathrm{pH}$ 3-squares; $\mathrm{pH} 4$-triangles; $\mathrm{pH}$ 5cross and $\mathrm{pH} 6$ - circle). As results from Fig. 4a, quinine, at $\mathrm{pH} 5$ and 6, is thermally stabile and long-time heating of its solution does not lead to a significant transformation/ 
<smiles>C=CC1CN2CCC1CC2[C@H](O)c1ccnc2ccc(OC)cc12</smiles>

1<smiles>COc1ccc2nccc([C@@H](O)C3CC4CCN3CC4C(C)O)c2c1</smiles>

4<smiles>C=CC1CN2CCC1CC2[C@H](O)c1ccnc2ccc(OC)cc12</smiles>

4<smiles>COc1ccc2nccc([C@@H](O)C3CC4CCN3CC4C(C)OC)c2c1</smiles>

7<smiles>C=CC1CN2CCC1CC2[C@H](O)c1ccnc2ccc(OC)cc12</smiles>

$7^{\prime}$<smiles>C=CC1CN2CCC1CC2[C@H](O)c1ccnc2ccc(OC)cc12</smiles>

2<smiles>COc1ccc2nccc([C@@H](O)C3CC4CCN3CC4C(C)O)c2c1</smiles>

5<smiles>C=CC1CN2CCC1CC2[C@H](O)c1ccnc2ccc(OC)cc12</smiles>

$5^{\prime}$<smiles>COc1ccc2nccc([C@@H](O)C3CC4CCN3CC4C(C)OC)c2c1</smiles>

8<smiles>C=CC1CNCC1CCC(=O)c1ccnc2ccc(OC)cc12</smiles>

3<smiles>COc1ccc2nccc(C(=O)CCC3CNCC3C(C)O)c2c1</smiles>

6<smiles>C=CC1CNCC2CCCCC12CO</smiles>

$6^{\prime}$<smiles>COc1ccc2nccc(C(=O)CCC3CNCC3C(C)OC)c2c1</smiles>

9 
Table 2 The HRMS data for quinine and quinine transformation products

\begin{tabular}{|c|c|c|c|c|c|}
\hline Compound & Elemental composition $[\mathrm{M}+\mathrm{H}]^{+}$ & Theoretical mass $[\mathrm{M}+\mathrm{H}]^{+}(\mathrm{Da})$ & Experimental mass $[\mathrm{M}+\mathrm{H}]^{+}(\mathrm{Da})$ & $\Delta \mathrm{mDa}$ & $\Delta \mathrm{ppm}$ \\
\hline $\mathrm{Qu}$ & $\mathrm{C}_{20} \mathrm{H}_{24} \mathrm{~N}_{2} \mathrm{O}_{2}$ & 325.1916 & 325.1921 & 0.5 & 1.5 \\
\hline epi-Qu & $\mathrm{C}_{20} \mathrm{H}_{24} \mathrm{~N}_{2} \mathrm{O}_{2}$ & 325.1916 & 325.1912 & -0.4 & -1.2 \\
\hline Qu-tox & $\mathrm{C}_{20} \mathrm{H}_{24} \mathrm{~N}_{2} \mathrm{O}_{2}$ & 325.1916 & 325.1923 & 0.7 & 2.2 \\
\hline $\mathrm{Qu}-\mathrm{OH}$ & $\mathrm{C}_{20} \mathrm{H}_{26} \mathrm{~N}_{2} \mathrm{O}_{3}$ & 343.2021 & 343.2021 & 0 & 0.0 \\
\hline epi-Qu-OH & $\mathrm{C}_{20} \mathrm{H}_{26} \mathrm{~N}_{2} \mathrm{O}_{3}$ & 343.2021 & 343.2021 & 0 & 0.0 \\
\hline Qu-tox-OH & $\mathrm{C}_{20} \mathrm{H}_{26} \mathrm{~N}_{2} \mathrm{O}_{3}$ & 343.2021 & 343.2021 & 0 & 0.0 \\
\hline $\mathrm{Qu}-\mathrm{OMe}$ & $\mathrm{C}_{21} \mathrm{H}_{28} \mathrm{~N}_{2} \mathrm{O}_{3}$ & 357.2178 & 357.2169 & -0.9 & -2.5 \\
\hline epi-Qu-OMe & $\mathrm{C}_{21} \mathrm{H}_{28} \mathrm{~N}_{2} \mathrm{O}_{3}$ & 357.2178 & 357.2173 & -0.5 & -1.4 \\
\hline Qu-tox-OMe & $\mathrm{C}_{21} \mathrm{H}_{28} \mathrm{~N}_{2} \mathrm{O}_{3}$ & 357.2178 & 357.2184 & 0.6 & 1.7 \\
\hline
\end{tabular}
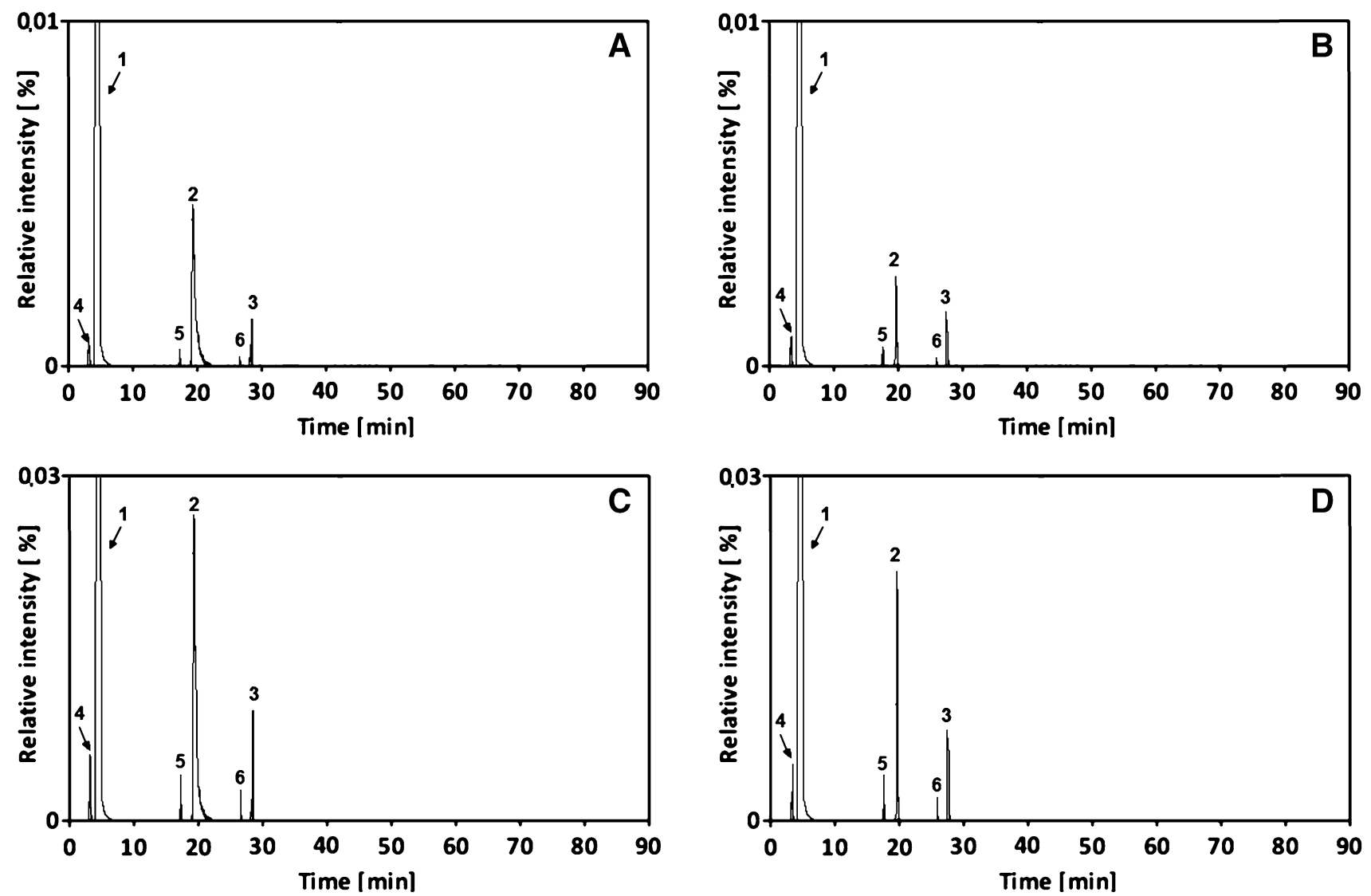

Fig. 3 Exemplary SIM chromatograms of Indian Tonic and Bitter Lemon without heating (a, b, respectively) and after heating under reflux for $0.5 \mathrm{~h}$ (c, $\mathbf{d}$, respectively). Peak numbers correspond to compounds numbers given in Table 1

degradation of the compound. At lower $\mathrm{pH}$, the quinine concentration decrease in the quinine solution is observed. At $\mathrm{pH} 2$ quinine is completely degraded just after $1 \mathrm{~h}$ heating. The relationships shown in Fig. $4 \mathrm{a}$ are in agreement with the literature data $[15,16]$.

According to the results presented in Fig. $4 \mathrm{~b}$ and c, the lengthening of heating time causes the concentration increase of $\boldsymbol{e p i - Q \mathbf { u }}$ and $\mathbf{Q u}-\mathbf{t o x}$, respectively. The formation speed of these compounds depends on $\mathrm{pH}$ : the smallest is at $\mathrm{pH} 6$ whereas the quickest at $\mathrm{pH} 2$. After $1 \mathrm{~h}$ heating of the quinine solution at $\mathrm{pH} 2$ and 3, the formation speed of $\boldsymbol{e p i - Q u}$ slows down, yet the increase of its concentration is still observed. In the case of Qu-tox, its concentration increase followed by decrease with heating time is seen. The observed plot suggests lower thermostability of Qutox than epi-Qu.

The influence of heating time at different $\mathrm{pH}$ on the formation of Qu-OH is illustrated in Fig. 4d. As appears from 

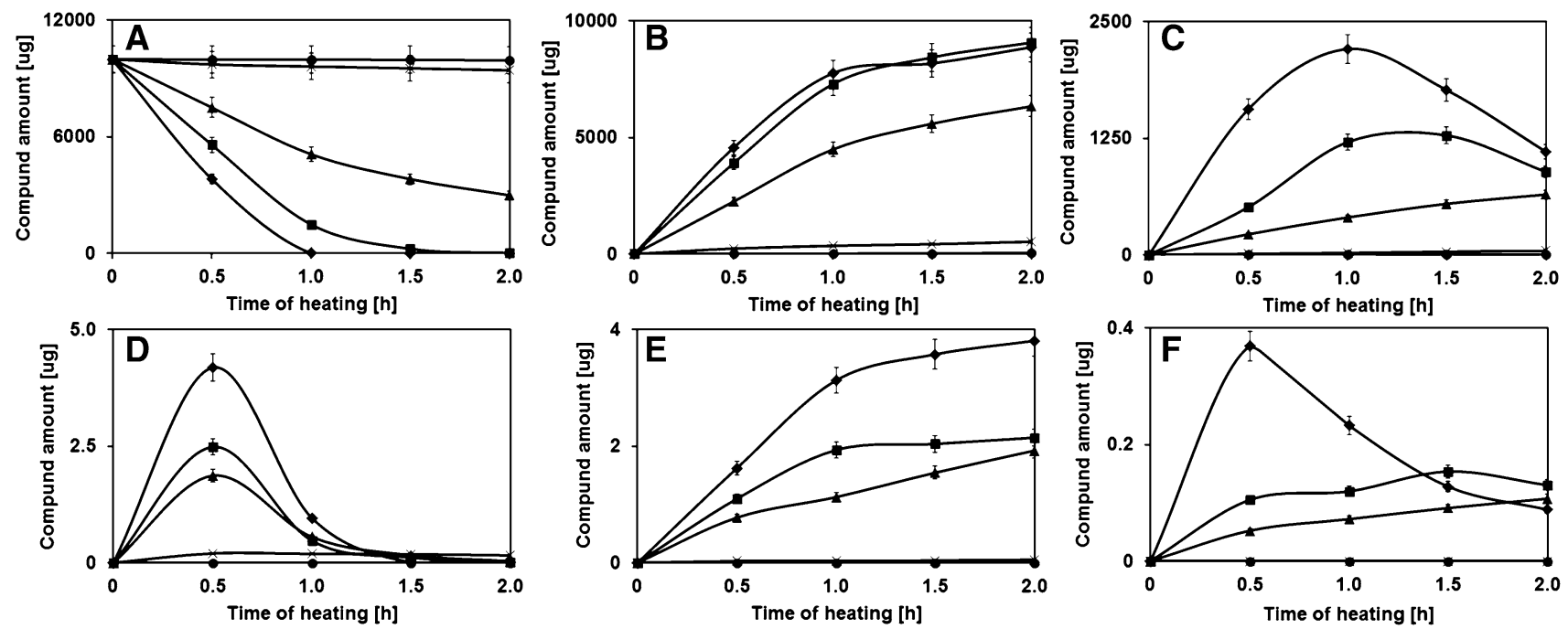

Fig. 4 The influence of heating time on the amount of quinine remaining in the heated quinine solution (a) and on the amount of individual quinine derivatives (epi-Qu, Qu-tox, Qu-OH, epi-Qu-OH and Qu-tox-OH-b-f, respectively), all formed during the heating of quinine in phosphoric buffer at $\mathrm{pH} 2$ (diamonds), $\mathrm{pH} 3$ (squares), $\mathrm{pH}$ 4 (triangles), $\mathrm{pH} 5$ (cross) and $\mathrm{pH} 6$ (circle) the plots, the increase of heating time in strongly acidic quinine solutions $(\mathrm{pH} 2-4)$ leads to the concentration increase of $\mathbf{Q u}-\mathbf{O H}$. The lower $\mathrm{pH}$, the greater $\mathbf{Q u}-\mathbf{O H}$ concentration. The decrease in $\mathbf{Q u}-\mathbf{O H}$ concentration during longer heating of quinine in strongly acidic solutions suggests thermo-lability of this hydroxylated quinine derivative. Taking this fact into consideration, it cannot be excluded that $\mathbf{Q u}-\mathbf{O H}$ is an intermediate state in the formation of epi-Qu -OH and Qu-tox-OH. A very small amount of Qu$\mathbf{O H}$ is formed at $\mathrm{pH} 5$, and the influence of heating time at this $\mathrm{pH}$ is very slight. Qu-OH does not form at $\mathrm{pH} 6$.

The concentration changes of epi-Qu-OH and Qu-tox$\mathbf{O H}$ vs. heating time of quinine solutions at different $\mathrm{pH}$ are presented in Fig. 4e and f, respectively. The formation speed of these compounds also depends on $\mathrm{pH}$. It is the slowest at $\mathrm{pH} 4$ and the quickest at $\mathrm{pH} 2$. These compounds do not form at $\mathrm{pH} 5$ and 6 as their precursors, epi-Qu and Qu-tox, do not form in this $\mathrm{pH}$ range. It should be stressed that graphs of epi-Qu amount in the heating time function for all $\mathrm{pH}$ levels (see Fig. 4b) are analogous for those corresponding to $\boldsymbol{e p i - Q u - O H}$ (see Fig. 4e). The analogy between the individual relationships can also be seen in the case of Qu-tox and Qu-tox-OH (compare Figs. 4c and 4f). Observed analogies may suggest that $\boldsymbol{e p i - Q u - O H}$ and $\mathbf{Q u}-$ tox-OH are formed from epi-Qu and Qu-tox, respectively.

Figure 5 shows the influence of heating time on the amount of quinine remaining in the heated quinine solution (Fig. 5a) and on the amount of individual quinine derivatives (epi-Qu, Qu-tox, Qu-OH, epi-Qu-OH, Qutox-OH, Qu-OMe, epi-Qu-OMe and Qu-tox-OMeFig. $5 \mathrm{~b}-\mathrm{i}$, respectively), all formed during the heating of quinine in methanol/phosphoric buffer $(75 / 25 \mathrm{v} / \mathrm{v})$, the solutions differing in $\mathrm{pH}(\mathrm{pH} 2$-diamonds; $\mathrm{pH} 3-$ squares; $\mathrm{pH} 4$-triangles; $\mathrm{pH} 5$-cross and $\mathrm{pH}$ 6-circle). Its analysis supports the following conclusions:

- the influence of heating time on the Qu degradation speed and on the formation speed of quinine structural isomers and their hydroxyl derivatives $(\mathbf{Q u}, \boldsymbol{e p i}$ Qu, Qu-tox, Qu-OH, epi-Qu-OH and Qu-tox-OH) in methanol/phosphoric buffer quinine solutions and in phosphoric buffer quinine solutions, for all $\mathrm{pH}$, is very similar (compare Figs. 4a-f, 5a-f). The lack of a clear maximum in the plot for Qu-tox-OH at $\mathrm{pH}$ 2 (see Fig. 5f-the curve marked with diamonds) is the main difference in quinine behavior in the systems with and without methanol. Moreover, the amounts of hydroxylated quinine derivatives formed in methanol/ phosphoric buffer $(75 / 25 \mathrm{v} / \mathrm{v})$ quinine solutions are markedly lower than those in methanol-free quinine solutions. Both effects are most probably connected with lower water concentration in methanol/phosphoric buffer quinine solutions;

- the influence of heating time and $\mathrm{pH}$ on the formation of methoxyl derivatives of quinine and its structural isomers (Qu-OMe, epi-Qu-OMe and Qu-tox-OMe) in methanol/phosphoric buffer quinine solutions is similar, just like as the influence of both parameters on the formation of hydroxyl derivatives of quinine and its structural isomers in phosphoric buffer quinine solutions. It must be stressed that in the range of pH 4-6, Qu-tox-OMe does not form at all during the heating of quinine solution in methanol/phosphoric buffer $(75 / 25 \mathrm{v} / \mathrm{v})$. 

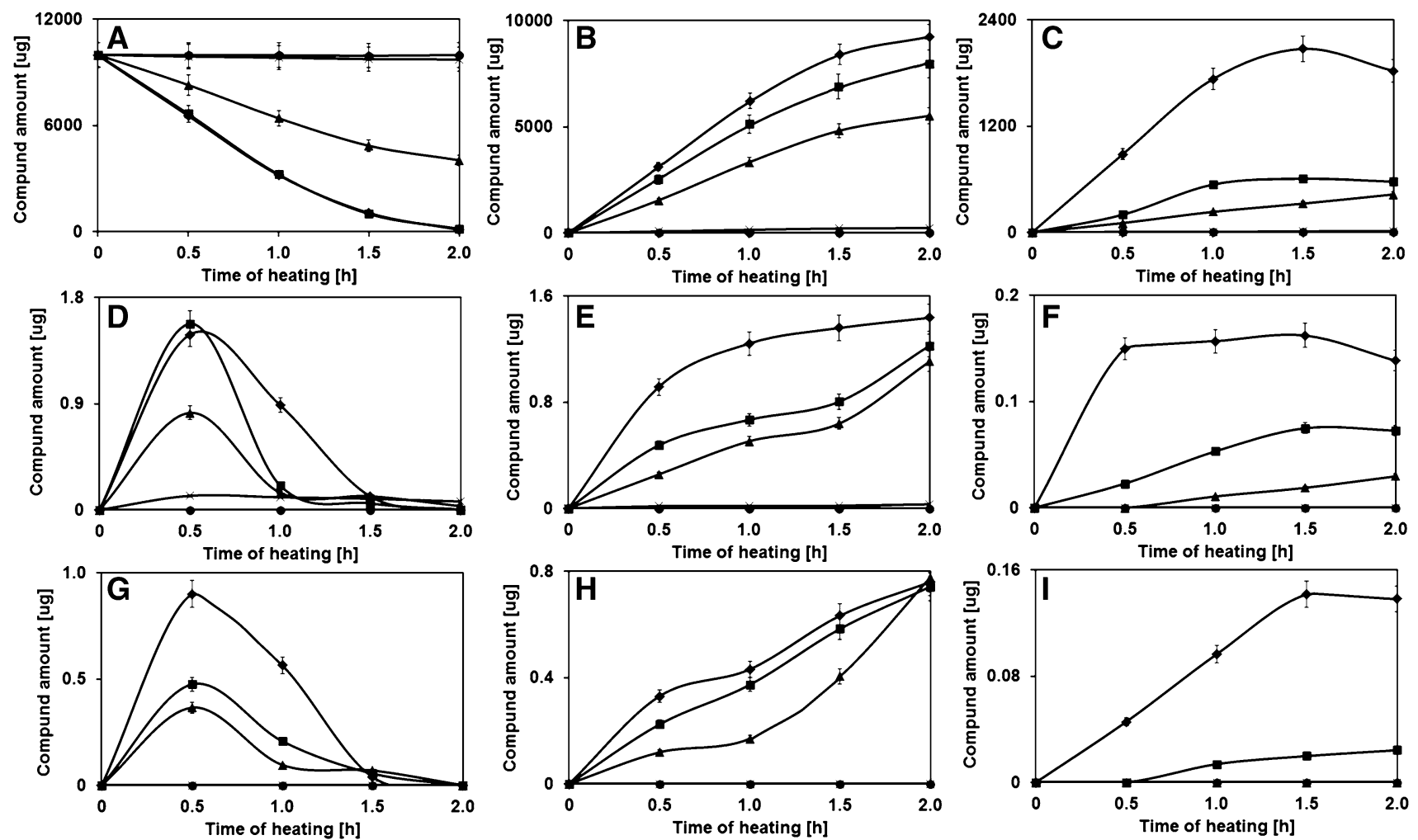

Fig. 5 The influence of heating time on the amount of quinine remaining in the heated quinine solution (a) and on the amount of individual quinine derivatives (epi-Qu, Qu-tox, Qu-OH, epi-QuOH, Qu-tox-OH, Qu-OMe, epi-Qu-OMe and Qu-tox-OMe) (b-i, respectively), all formed during the heating of quinine in methanol/ phosphoric buffer (75/25 v/v) solutions at $\mathrm{pH} 2$ (diamonds), $\mathrm{pH} 3$ (squares), $\mathrm{pH} 4$ (triangles), $\mathrm{pH} 5$ (cross) and $\mathrm{pH} 6$ (circle)
Figure 6 illustrates the influence of methanol concentration on the amount of the remaining Qu (Fig. 6a) and on the amounts of epi-Qu, Qu-tox (Fig. 6a), Qu-OH, epi-QuOH, Qu-tox-OH (Fig. 6b) Qu-OMe, epi-Qu-OMe and Qu-tox-OMe (Fig. 6c) forming in methanol/phosphoric buffer ( $\mathrm{pH}$ 2) quinine solutions heated under reflux for $2 \mathrm{~h}$. In these figures, the curves with diamonds represent $\mathbf{Q u}$, $\mathbf{Q u}-\mathbf{O H}$, and Qu-OMe, the curves with squares correspond to epi-Qu-OH, and epi-Qu-OMe, whereas Qu-tox, Qu-tox-OH and Qu-tox-OMe are reflected by the curves with triangles. As results from the figure, at the specified conditions:

- the total Qu transformation is observed when the concentration of methanol in quinine solution is lower than 75\% (see the curve with diamonds in Fig. 6a). In pure methanol, $\mathbf{Q u}$ remains totally stable;

- the transformation degree of Qu to its structural isomers, epi-Qu and Qu-tox, is almost constant in the methanol concentration range $0-75 \%$ (see the curves with diamonds, squares and triangles, respectively, in Fig. 6a). The concentration decrease of these isomers, at a simultaneous $\mathbf{Q u}$ concentration increase in the metha- nol concentration range $75-100 \%$, confirms the necessity of the presence of a strongly acidic aqueous environment for $\mathrm{Qu}$ isomerization;

- the increase of methanol concentration in the range 25-100\% leads to the decrease of epi-Qu-OH, Qutox-OH (see the curves with squares and triangles, respectively, in Fig. 6b). These trends are obvious and result from the gradually diminished amount of water in the examined systems;

- the concentration increase followed by the concentration decrease with the methanol concentration for epiQu-OMe and Qu-tox-OMe is observed (see the curves with squares and triangles, respectively, in Fig. 6c). The growing parts of these relationships are obvious as they result from methanol concentration increase in the examined systems. The concentration decrease of quinine methoxyl derivatives can be explained by:

- the water concentration decrease in the system, which is responsible for the formation of carbocation (the intermediate form in the formation of quinine methoxyl derivatives), if the addition of water to double bond in $\mathbf{Q u}$, during its transformation, occurs, or 

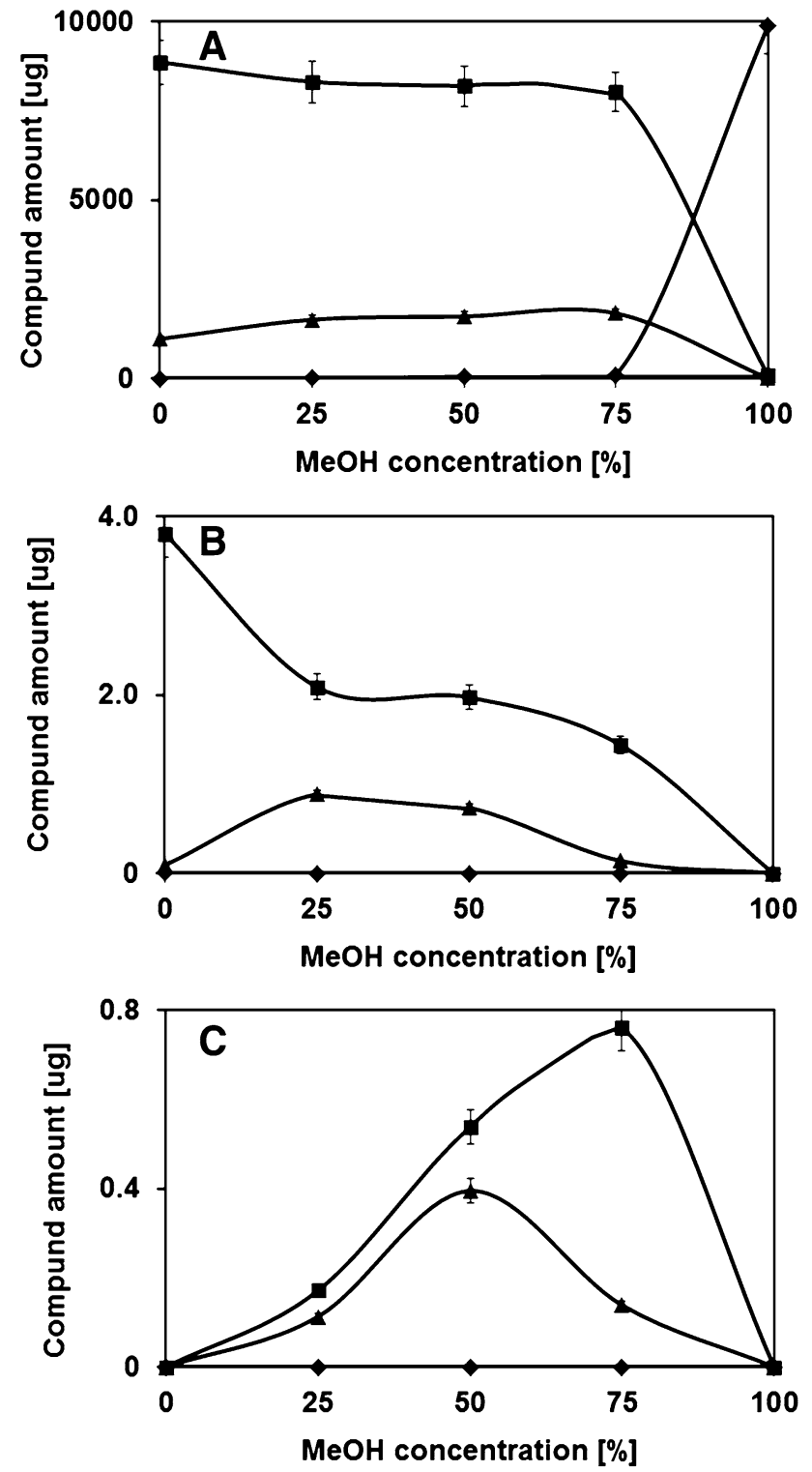

Fig. 6 The influence of methanol concentration on the amount of the remaining $\mathbf{Q u}$ (diamonds) (a) and amounts of forming epi-Qu (squares), Qu-tox (triangles) (a), Qu-OH (diamonds), epi-Qu-OH (squares), Qu-tox-OH (triangles) (b) Qu-OMe (diamonds), epi-QuOMe (squares) and Qu-tox-OMe (triangles) (c) in methanol/phosphoric buffer ( $\mathrm{pH}$ 2) quinine solutions heated under reflux for $2 \mathrm{~h}$

- the decrease of nitrogen protonation degree of $\mathbf{Q u}$, if coordination of water with one $\mathbf{Q u}$ nitrogen takes place.

\section{Conclusions}

According to $[15,16]$, quinine transforms to its structural isomers in the strongly acidic water environment. In the course of detailed investigations, we observed that this process occurs also in less acidic water and methanol/ water solutions. Moreover, in addition to structural quinine isomers, hydroxyl derivatives of quinine itself and its structural isomers are additionally formed in these environments. Moreover, methoxy derivatives of quinine and its structural isomers also appear in buffered methanol/water system. All the hydroxyl and methoxyl derivatives of quinine constitute newly discovered compounds. The amount of each formed component depends on the heating time, concentration of alcohol and on the solvent $\mathrm{pH}$.

The presented results are important both for the analytical and preparative purposes:

1. The transformation products of quinine identified in this study can be mistakenly treated as new components, not naturally present in the plant. Hence, our results are especially useful for researchers investigating plant metabolism and looking for new plant components.

2. Quinine derivatives, quinine structural isomers and their derivatives can be formed in significant amounts. As their bioactivity is still unknown, our findings should be brought to the attention of quinine products.

It is worth mentioning that the presented data are in certain contrary to the reports concerning (bio)transformation of quinine and its derivatives [18]. Following [18], these compounds are transformed to demethyl and dearomatic products and to hydroxyl derivatives with hydroxyl group attached to another position in carbon ring of quinine than that indicated in our experiments. This is obvious as (bio)transformation pathway occurring in living organisms is catalyzed by enzymes and often does not comply with the rules of classical organic synthesis.

Acknowledgements The research was carried out with the equipment purchased thanks to the financial support of the European Regional Development Fund in the framework of the Operational Program Development of Eastern Poland 2007-2013 (Contract No. POPW.01.03.00-06-009/11-00, Equipping the laboratories of the Faculties of Biology and Biotechnology, Mathematics, Physics and Informatics, and Chemistry for studies of biologically active substances and environmental samples.

\section{Compliance with ethical standards}

Conflict of interest The authors declare that there is no conflict of interests.

Compliance with ethics requirements This article does not contain any studies with human or animal subjects.

Open Access This article is distributed under the terms of the Creative Commons Attribution 4.0 International License (http:// creativecommons.org/licenses/by/4.0/), which permits unrestricted 
use, distribution, and reproduction in any medium, provided you give appropriate credit to the original author(s) and the source, provide a link to the Creative Commons license, and indicate if changes were made.

\section{References}

1. Caner H, Biedermann PU, Agranat I (2003) Conformational spaces of cinchona alkaloids. Chirality 15:637-645

2. Dorndorp A, Nosten F, Stepniewska K, Day N, White N (2005) Artesunate versus quinine for treatment of severe falciparum malaria: a randomised trial. Lancet 366:717-725

3. Faouzi MA, Khalfi F, Dine T, Luyckx M, Brunet C, Gressier B, Goudaliez F, Cazin M, Kablan J, Belabed A, Cazin JC (1999) Stability, compatibility and plasticizer extraction of quinine injection added to infusion solutions and stored in polyvinyl chloride (PVC) containers. J Pharm Biomed Anal 21:923-930

4. Jamaludin A, Mohamad M, Navaratnam V, Selliah K, Tan SC, Wernsdorfer WH, Yuen KH (1988) Relative bioavailability of the hydrochloride, sulphate and ethyl carbonate salts of quinine. Br J Clin Pharmacol 25:261-263

5. Silva THA, Oliveira AB, de Almeida WB (1997) Conformational analysis of the antimalarial agent quinine. Struct Chem 8:95-107

6. Dawidowicz AL, Wianowska D (2009) Application of the MSPD technique for the HPLC analysis of rutin in Sambucus nigra L.: the linear correlation of the matrix solid-phase dispersion process. J Chromatogr Sci 47:914-918

7. Kress H (2013) Practical Herbs 2, 1st edn. Yrtit ja yrttiterapia Henriette Kress, Helsinki

8. Vishwanath K, Vishwananthan K, Latha C, Thangaraj SA (2011) A direct method for preparing quinine hydrochloride from cinchona bark. $\mathrm{Nr}$ of publication: WO2011161691 A1

9. Dawidowicz AL, Bernacik K, Typek R (2016) Rutin transformation during its analysis involving extraction process for sample preparation. Food Anal Methods 9:213-224
10. Dawidowicz AL, Typek R (2010) Thermal stability of 5- $O$-caffeoylquinic acid in aqueous solutions at different heating conditions. J Agric Food Chem 58:12578-12584

11. Dawidowicz AL, Typek R (2011) The influence of $\mathrm{pH}$ on the thermal stability of 5-O-caffeoylquinic acids in aqueous solutions. Eur Food Res Technol 233:223-232

12. Dawidowicz AL, Typek R (2012) Formation of ester and amine derivatives of 5-O-caffeoylquinic acid in the process of its simulated extraction. J Agric Food Chem 60:12289-12295

13. Wan JW, Ma XB, He RX, Li M (2014) An easy route to exotic 9-epimers of 9-amino-(9-deoxy) cinchona alkaloids with (8S, 9R) and (8R, 9S)-configurations through two inversions of configuration. Chin Chem Lett 25:557-560

14. Wiles JA, Phadke AS, Bradbury BJ, Pucci MJ, Thanassi JA, Deshpandle M (2011) Selenophene-containing inhibitors of type IIA bacterial topoisomerases. J Med Chem 54:3418-3425

15. Gorka AP, Sherlach KS, de Dios AC, Roepe PD (2013) Relative to quinine and quinidine, their 9-epimers exhibit decreased cytostatic activity and altered heme binding but similar cytocidal activity versus Plasmodium falciparum. Antimicrob Agents Chemother 57:365-374

16. Smith AC, Williams RM (2008) Communication Rabe rest in peace: confirmation of the Rabe-Kindler conversion of $d$-quinotoxine to quinine: experimental affirmation of the WoodwardDoering formal total synthesis of quinine. Angew Chem Int Ed 47:1736-1740

17. McMurry J (2007) Organic chemistry, vol 7. Brooks/Cole-Thomson, Belmont

18. Marcsisin SR, Jin X, Bettger T, McCulley N, Sousa JC, Shanks GD, Tekwani BL, Sahu R, Reichard GA, Sciotti RJ, Melendez V, Pybus BS (2013) CYP450 phenotyping and metabolite identification of quinine by accurate mass UPLC-MS analysis: a possible metabolic link to blackwater fever. Malar J 12:214 